\title{
Design and performance evaluation of a photocatalytic reactor for indoor air disinfection
}

\author{
Silvia Mercedes Zacarías $^{1}$ (D) $\cdot$ Agustina Manassero $^{1} \cdot$ Silvana Pirola $^{1} \cdot$ Orlando Mario Alfano $^{1} \cdot$ María Lucila Satuf $^{1}$
}

Received: 29 July 2020 / Accepted: 12 November 2020 / Published online: 21 November 2020

(C) Springer-Verlag GmbH Germany, part of Springer Nature 2020

\begin{abstract}
Since COVID-19 pandemic, indoor air quality control has become a priority, and the development of air purification devices effective for disinfecting airborne viruses and bacteria is of outmost relevance. In this work, a photocatalytic device for the removal of airborne microorganisms is presented. It is an annular reactor filled with $\mathrm{TiO}_{2}$-coated glass rings and irradiated internally and externally by UV-A lamps. B. subtilis spores and vegetative cells have been employed as model biological pollutants. Three types of assays with aerosolized bacterial suspensions were performed to evaluate distinct purification processes: filtration, photocatalytic inactivation in the air phase, and photocatalytic inactivation over the $\mathrm{TiO}_{2}$-coated rings. The radiation distribution inside the reactor was analysed by performing Monte Carlo simulations of photon absorption in the photocatalytic bed. Complete removal of a high load of microorganisms in the air stream could be achieved in $1 \mathrm{~h}$. Nevertheless, inactivation of retained bacteria in the reactor bed required longer irradiation periods: after $8 \mathrm{~h}$ under internal and external irradiation, the initial concentration of retained spores and vegetative cells was reduced by $68 \%$ and $99 \%$, respectively. Efficiency parameters were also calculated to evaluate the influence of the irradiation conditions on the photocatalytic inactivation of bacteria attached at the coated rings.
\end{abstract}

Keywords Bioaerosols $\cdot$ Air purification device $\cdot$ Packed bed $\cdot$ Photocatalysis $\cdot$ Efficiency parameters $\cdot$ Radiation absorption

\section{Introduction}

For many years, efforts from the scientific community have been conducted towards the development of efficient indoor air purification technologies. The US Environmental Protection Agency (USEPA) reported in 1989 the potential impact on human health of indoor air pollution. This concern was mainly due to the fact that people in industrialized societies spend approximately $90 \%$ of their time indoors (U.S. EPA 1989), where the concentrations of pollutants are often 2 to 5 times higher than typical outdoor concentrations.

Responsible Editor: Sami Rtimi

Silvia Mercedes Zacarías

szacarias@intec.unl.edu.ar

1 Instituto de Desarrollo Tecnológico para la Industria Química (INTEC, UNL-CONICET), Colectora RN 168 Km 472, 3000 Santa $\mathrm{Fe}$, Argentina
Indeed, indoor air quality control is now a priority, since the severe acute respiratory syndrome coronavirus 2 (SARSCoV-2) has impacted in most countries around the world. Millions of positives cases have been reported, resulting in hundreds of thousands of deaths. Therefore, the development of air purification devices effective for disinfecting airborne viruses and bacteria is attracting worldwide attention.

Photocatalysis is a well-known air treatment technology for the removal of airborne chemical and biological pollutants. The photocatalytic removal of VOCs (volatile organic compounds) in air has been widely reported in the literature, and it has been summarized in recent studies (Luengas et al. 2015; Ren et al. 2017; Costa Filho and Vilar 2019). Many research groups have dedicated their efforts in either developing new types of photoreactors or improving the existent designs, such as (i) packed-bed photoreactors, (ii) monolithic photoreactors, (iii) photocatalytic membrane reactors, and (iv) microreactors (Costa Filho and Vilar 2019; Assadi et al. 2014).

In contrast to photocatalysis applied to chemicals, photocatalytic disinfection of contaminated air remained scarcely studied due to the complexity of working with bioaerosols, 
which combines difficulties inherent to microbiology and to aerosol sciences (Josset et al. 2010). Nevertheless, new promising photocatalytic materials and reactor designs have been recently reported in the literature. To study the inactivation of bacteria and fungi, Rodrigues-Silva et al. (2016) carried out experiments in a single-pass annular photoreactor packed with cellulose acetate monolithic structures coated with P25. They found that the survival rate of the microorganisms under study decreased with the catalyst load and the UVA exposure time. Inactivation of fungi (A. fumigatus, $80 \%$ ) was slower than Gram-positive bacteria (S. aureus, $88 \%$ ), followed by Gramnegative bacteria (Pseudomonas aeruginosa, 92\%) and resistant bacteria (methicillin-resistant Staphylococcus aureus, 93\%). Doss et al. (2018) designed a small-size, flow-through structured photocatalytic device $(40 \mathrm{~mm} \times 65 \mathrm{~mm})$ for purifying air from airborne T2 bacteriophage viruses. They used LEDs at $392 \mathrm{~nm}$ as irradiation light source and $\mathrm{TiO}_{2} / \beta-\mathrm{SiC}$ solid alveolar foams as photocatalytic media. A logarithmic abatement of 3 for $60 \mathrm{~min}$ of run time was observed. Also, Kim and Jang (2018) tested VUV photocatalysis for inactivating airborne MS2 viruses using pleated and spiraltype $\mathrm{Pd}-\mathrm{TiO}_{2}$ catalysts and short irradiation times $(0.004$ $0.125 \mathrm{~s}$ ) in a continuous annular photoreactor. They obtained more than $90 \%$ inactivation for MS2 viruses. Recently, Li et al. (2019) studied the photocatalytic bactericidal properties of air filters fabricated from zinc-imidazolate metal organic frameworks (ZIF-8 MOF). They built a rectangular chamber $(30 \times 30 \times 60 \mathrm{~cm})$, assumed to be an air duct model, which was divided into an inlet section, a reaction section, and an outlet section by the MOFilter. The filter was exposed to Escherichia coli-containing aerosols under simulate sunlight illumination for $30 \mathrm{~min}$. They analysed the viability of airborne bacteria in the air outlet and over the photocatalytic filters. They obtained a good performance for integrated pollution control, with $>99.99 \%$ photocatalytic killing efficiency against $E$. coli in $30 \mathrm{~min}$ and $97 \%$ particulate matter removal.

The selection of the model microorganism to test the effectiveness of purification devices is a relevant issue. Bacterial spores have distinctive features crucial to their survival under adverse conditions, which make them more resistant to disinfection techniques. This characteristic has been explained by considering their structure, morphology, and chemical composition (Atrih and Foster 2002). Therefore, spores of Bacillus species are good candidates to act as biological indicators in disinfection processes. If spore inactivation is accomplished, it is very probable that inactivation of less resistant microorganisms has also been attained.

The photocatalytic mechanism to inactivate biological pollutants is associated to the oxidation of the organic components of the microorganism cells through photogenerated holes or radicals, analogous to the photocatalytic degradation of organic pollutants (Josset et al. 2010). Although there are many hypotheses about the reactive oxygen species that are responsible for the inactivation, most researchers agree that the $\cdot \mathrm{OH}$ radical is the primary oxidant (Horie et al. 1998a, b; Blake et al. 1999; Pal et al. 2005; Vohra et al. 2005; Yu et al. 2008). In a previous work (Zacarías et al. 2010), a simplified scheme was proposed for the complex photocatalytic inactivation process of $B$. subtilis spores. In the suggested mechanism, $\bullet \mathrm{OH}$ radicals were the main responsible species for the damage of the spore's coat and core, which finally led to the microorganism inactivation.

To evaluate the disinfection efficiency of photocatalytic reactors, the knowledge of the spatial distribution of the absorbed radiation represents a key factor. Stochastic simulation methods, like the Monte Carlo method, are preferred to solve radiation models in reactors with complex geometries (Moreira et al. 2010). The Monte Carlo method has been successfully employed to evaluate the photon absorption distribution inside reactors with different geometries, radiation sources, and catalyst arrangements (Imoberdorf et al. 2010; Zazueta et al. 2013; Marugán et al. 2015; Akach and Ochieng 2018).

In a recent publication, our group reported the photocatalytic inactivation of airborne Bacillus subtilis spores and vegetative cells in a packed-bed reactor filled with $\mathrm{TiO}_{2}$-coated glass rings and irradiated with UV-A lamps (Zacarías et al. 2019). The aim of the designed reactor was to combine two processes for air disinfection: the retention of airborne microorganisms in the reactor bed (filtration) and the photocatalytic inactivation of the retained microorganisms. After the pass of polluted air through the reactor during $10 \mathrm{~min}$, the inactivation was assessed by measuring the viability of the microorganisms retained by the coated glass rings inside the reactor. At the end of the experiments ( $12 \mathrm{~h}$ of irradiation), the initial concentration of retained spores and vegetative cells was reduced by almost $55 \%$ and $96 \%$, respectively. The purpose of the present work is to improve the design of the reactor for indoor air disinfection. A new illumination arrangement has been constructed, and a system to recycle the polluted air has been introduced in the experimental setup. The radiation distribution inside the reactor is analysed by performing Monte Carlo simulations of photon absorption in the photocatalytic bed. Bacterial spores and vegetative cells are aerosolized inside the reactor, and the air stream is recycled under irradiation supplied by external and internal UV-A lamps, simultaneously and alternatively. The viability of microorganisms retained in the reactor bed and present in the air flow is evaluated under different experimental conditions. Finally, efficiency parameters are calculated to assess the use of light inside the reactor for air disinfection.

The novelty of the present work relies on (1) the assessment of distinct processes (filtration and photocatalytic inactivation) for bioaerosol remediation in a photocatalytic reactor employing the resistant form of a model microorganism and (2) the analysis of the effect of the absorbed radiation, 
computed by Monte Carlo simulations, on the reactor performance for the inactivation of the retained bacteria.

\section{Experimental}

\section{Materials}

\section{Photocatalytic packing material}

Borosilicate glass rings $(0.4-\mathrm{cm}$ diameter $\times 0.8-\mathrm{cm}$ length $)$ were employed as support to immobilize the $\mathrm{TiO}_{2}$ catalyst. Among the advantages of choosing glass rings as packing material, we can cite high transmittance in the UV-A region, resistance to the high temperatures employed in the coating procedure, and low air pressure drop.

Titanium dioxide AEROXIDE® TiO2 P25 (Evonik, Germany) was employed for the coatings. Catalyst immobilization on the glass rings was performed by the dip-coating technique (Zacarías et al. 2019). Briefly, the rings were vertically immersed in the catalyst suspension $\left(150 \mathrm{~g} \mathrm{~L}^{-1}\right)$ and withdrawn at a speed of $3 \mathrm{~cm} \mathrm{~min}^{-1}$. Then, they were dried $\left(110{ }^{\circ} \mathrm{C}\right.$ for $\left.24 \mathrm{~h}\right)$ and calcined $\left(500{ }^{\circ} \mathrm{C}\right.$ for $\left.2 \mathrm{~h}, 1^{\circ} \mathrm{min}^{-1}\right)$.

The mass of $\mathrm{TiO}_{2}$ per unit area of the support, obtained from the weight difference of a significant number of rings, was $0.28 \pm 0.03 \mathrm{mg} \mathrm{cm}^{-2}$. The thickness of the $\mathrm{TiO}_{2}$ film, determined from the SEM images, was $0.73 \pm 0.03 \mu \mathrm{m}$. The coated rings were reused several times in different inactivation assays. After each assay, they were sterilized at $160^{\circ} \mathrm{C}$ for $2 \mathrm{~h}$. It has been demonstrated that the coated rings maintain the photocatalytic activity without significant changes up to ten irradiation cycles (Zacarías et al. 2019).

\section{Model microorganism}

Inactivation tests were carried out with vegetative cells and spores of Bacillus subtilis (ATCC 6633 strain). They are Gram-positive, rod-shaped, endospore forming bacteria, commonly found in soil and rotting plant material.

Suspensions with approximately $10^{8} \mathrm{CFU}$ (colony forming units) $\mathrm{mL}^{-1}$ of bacteria were used for bioaerosol generation. Spore suspensions were obtained following the technique proposed by Shehata and Collins (1972). They were stored in sterile distilled water at $4{ }^{\circ} \mathrm{C}$ for up to 2 months.

\section{Methods}

\section{Experimental setup}

As depicted in Fig. 1, the photocatalytic device is a horizontally held, annular reactor with recycle. It is made of borosilicate glass with $4.0-\mathrm{cm}$ inner tube diameter and $10.5-\mathrm{cm}$ outer tube diameter. The reactor is equipped with a special mobile

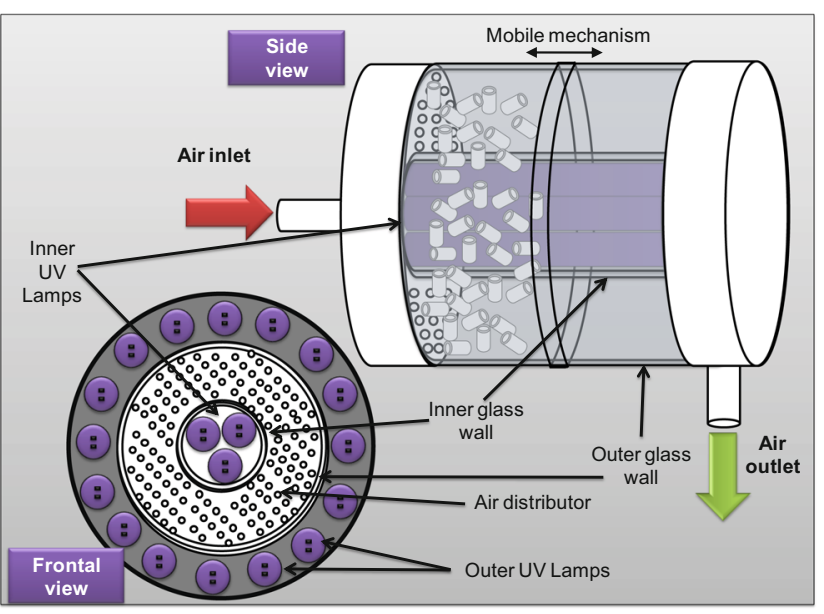

a) Reactor scheme and UV lamps distribution

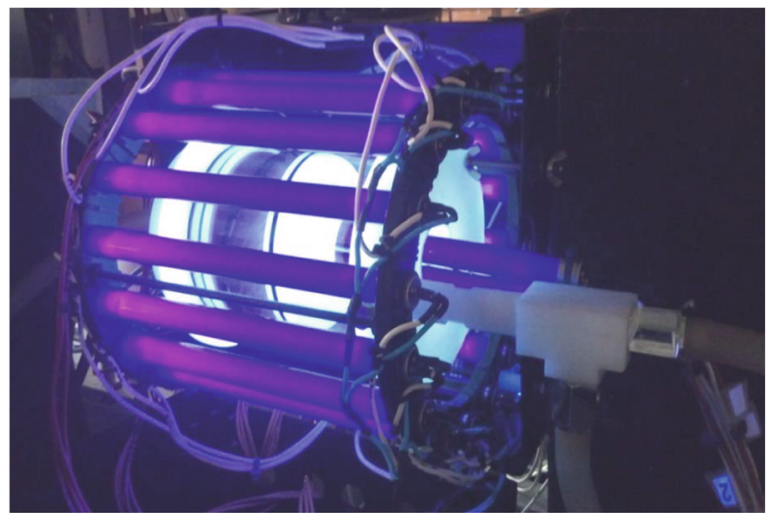

b) Picture of the reactor with inner and outer UV lamps turned on

Fig. 1 Photocatalytic reactor

mechanism that allows changing the reactor length from 1 to $10 \mathrm{~cm}$. This feature gives the device great flexibility to make experiments under different operating conditions, with different packing materials and with diverse type of pollutants. Based on preliminary tests, a length of $3 \mathrm{~cm}$ provided a satisfactory retention percentage of bacterial cells. Therefore, the reactor length was fixed at $3 \mathrm{~cm}$. Six hundred glass rings were employed to completely fill the 3 -cm-long annular reaction space in a random disposition.

The reactor inlet contains a perforated plate that acts as an air distributor to ensure uniform distribution of the polluted air in the reaction bed (Fig. 1a). The pressure drop in the reactor, calculated with Ergun equation at 12 LPM, is less than 0.1 mbar.

The UV radiation emitting system consists of two arrangements of tubular black-light fluorescent lamps (Satellite F6T5 BLB 6W). Internal irradiation is supplied by 3 lamps placed in the axis of the annulus. External irradiation is provided by 16 lamps spaced equidistantly around the reactor outer tube. They are surrounded by an enclosure that prevents UV-A exposure during operation. This enclosure contains a fan to cool the lamps and maintain constant temperature during the experiments. 
The incident radiation flux at the reactor windows was measured using a miniature spectrophotometer with an optical fibre (USB 2000 + UV-VIS-ES Ocean Optics). The average of the inner and outer incident radiation fluxes are $3.43 \mathrm{~mW}$ $\mathrm{cm}^{-2}$ and $1.89 \mathrm{~mW} \mathrm{~cm}^{-2}$, respectively. The emission spectra of the lamps is comprised between 300 and $400 \mathrm{~nm}$ with a maximum at $355 \mathrm{~nm}$ (UV-A).

The experimental setup (Fig. 2) also includes a synthetic air cylinder, a nebulizer (6 jet "Collison" type), a microorganism sampler (single-stage viable particle sampler), and a recirculation peristaltic pump (Apema SRL, BS6D). The nebulizer, containing the bacterial suspension, is connected to the reactor inlet through silicone tubing. At the reactor outlet, two valves allow the air flow to pass alternatively through the microorganism sampler, or along the recycle, also constructed with silicone tubing.

Inactivation tests were performed under 3 irradiation conditions: internal irradiation (only inner lamps on), external irradiation (only outer lamps on), and internal + external irradiation (inner and outer lamps on).

\section{Test procedure}

Previous experiments revealed that the viability of spores and vegetative cells over uncoated glass rings under UV-A light, and over $\mathrm{TiO}_{2}$-coated glass rings in the absence of UV-A light, was not significantly affected (Zacarías et al. 2019). Therefore, the effect of photolysis and catalytic inactivation in the dark can be safely neglected.

Three types of assays were performed to evaluate distinct processes: (i) filtration of microorganisms (spores) present in the air stream by adsorption in the packed bed, (ii) photocatalytic inactivation of microorganisms (spores) present in the air stream, and (iii) photocatalytic inactivation of microorganisms (spores and vegetative cells) retained in the packed bed.

i) Filtration of microorganisms in the air stream To evaluate the adsorption of microorganisms in the packed bed, spore suspensions of the same initial concentration were nebulized during $10 \mathrm{~min}$ at an air flow rate of 12 LPM inside the empty reactor (without filling) and, alternatively, in the reactor filled with the coated glass rings (exhaust valve open). During nebulization, samples were collected every 2 min by allowing the outlet air to impact $5 \mathrm{~s}$ in a culture plate with nutrient agar (Merck Chemicals) placed in the microorganism sampler (Fig. 2). When the sampler was not connected, the outlet air passed through a liquid impinger filled with sodium hypochlorite solution before being released to the atmosphere.

The culture plates were incubated at $30{ }^{\circ} \mathrm{C}$ for $48 \mathrm{~h}$, and the CFU were counted. The percentage of filtered spores is calculated as:

$\%$ filtered spores $=\left(\mathrm{CFU}_{\text {empty }}-\mathrm{CFU}_{\text {bed }}\right) / \mathrm{CFU}_{\text {empty }} \times 100$

ii) Photocatalytic inactivation of microorganisms in the air stream (with recirculation) Before each inactivation experiment with recirculation, spore suspensions were nebulized during $5 \mathrm{~min}$ at 12 LPM air flow rate inside the packed-bed reactor (exhaust valve open). Then, the exhaust valve was closed, and the polluted air was allowed to recirculate in the system at 3 LPM (pump on) with the lamps off. To assure that adsorption equilibrium between spores and the experimental device (reactor, tubing, connectors, and valves) is reached, several samples of the air stream were analysed with the microorganism sampler. Constant spore concentration was obtained after 30 minutes of recirculation in the dark (stabilization time, without irradiation). Subsequently, UV lamps were turned on (the pump remained on) and the inactivation experiments started. Air samples were taken at different time intervals (0, 20, 40,60 , and $80 \mathrm{~min}$ ) by allowing the recirculating air to impact $30 \mathrm{~s}$ on a nutrient agar plate located in the microorganism sampler. The culture procedure was the same as that reported in (i). This experiment was carried out with inner and outer lamps simultaneously on internal + external irradiation.
Fig. 2 Complete experimental setup

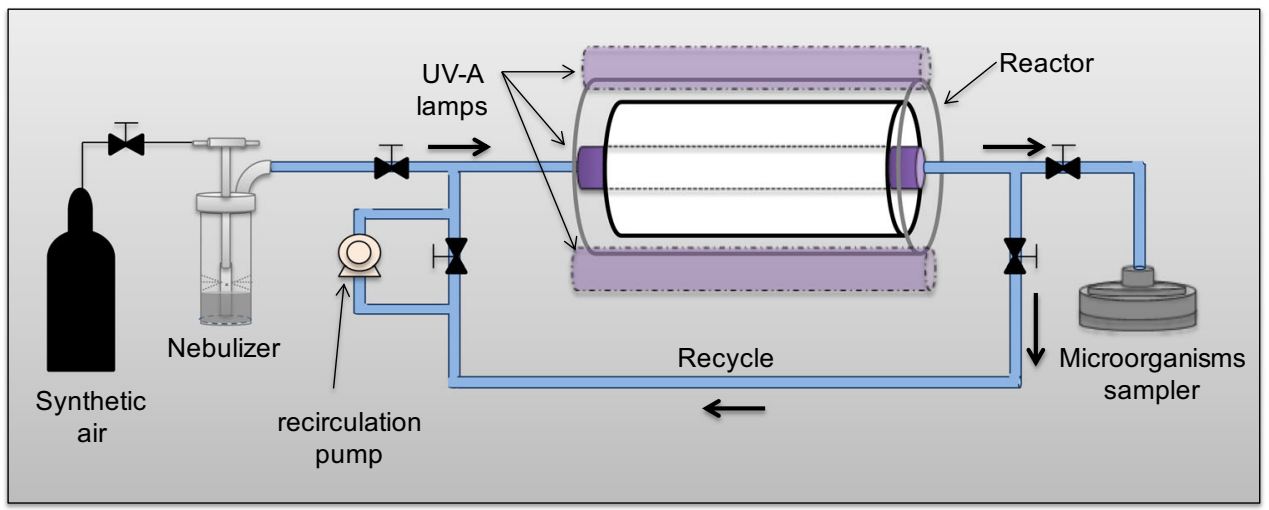


To evaluate the percentage of spores inactivated in the air stream at each sampling time $t$, the following equation was employed:

\%inactivated spores in the air $=\left(\mathrm{CFU}_{0}-\mathrm{CFU}_{\mathrm{t}}\right) / \mathrm{CFU}_{0} \times 100$

In this type of experiments, $\mathrm{CFU}_{0}$ corresponds to the sample taken immediately after the stabilization time.

iii) Photocatalytic inactivation of microorganisms in the packed bed (without recirculation) Before each inactivation experiment without recirculation, spores and, alternatively, vegetative cell suspensions were nebulized during $5 \mathrm{~min}$ at 12 LPM air flow rate inside the packed-bed reactor (exhaust valve open). Then, the exhaust valve was closed, and 9 glass rings were taken from different representative locations of the packed bed. Next, the lamps were turned on and the inactivation experiment started. The packed bed was irradiated during 8 h. Every 2 h, 9 glass rings were removed from the reactor. To count the number of viable spores or vegetative cells attached at the $\mathrm{TiO}_{2}$-coated rings, each set of 9 rings was placed in tubes with an extraction solution ( $0.1 \%$ peptone in distilled water with $0.01 \%$ of Tween 80 ), stirred, and then sonicated. Finally, aliquots of the resulting suspension were diluted and spread onto nutrient agar plates, incubated at $30{ }^{\circ} \mathrm{C}$ for $48 \mathrm{~h}$, and the $\mathrm{CFU}$ were counted. The extraction step was performed in triplicate ( 3 rings per tube), and the counting of the viable spores of each triplicate was performed, in turn, in duplicate. This experiment was carried out under 3 irradiation conditions: only inner lamps on (internal), only outer lamps on (external), and inner and outer lamps on (internal + external). It should be mentioned that when internal irradiation was employed, the inactivation rate was very low, so the experiments lasted $12 \mathrm{~h}$, and sampling was carried out every $4 \mathrm{~h}$.

To assess the photocatalytic inactivation of the microorganisms attached at the coated rings, the decay of viable spores or vegetative cells was fitted with the exponential equation:

$N=N_{0} \exp (-k t)$

where $\left.N(\mathrm{CFU} \mathrm{cm})^{-2}\right)$ is the bacterial concentration per unit area of the support, $\left.N_{0}(\mathrm{CFU} \mathrm{cm})^{-2}\right)$ is the initial bacterial concentration per unit area of the support, $k\left(\mathrm{~h}^{-1}\right)$ is the apparent kinetic constant, and $t(\mathrm{~h})$ is the irradiation time. The area of support was calculated as the sum of the internal and external surface of the 3 glass rings in each extracting tube.

Also, the percentage of inactivation and the logarithmic reduction (LR) after $8 \mathrm{~h}$ of irradiation were calculated as:

\%inactivated spores or cells in the packed-bed $=\left(N_{0}-N_{f}\right) / N_{0} \times 100$

$\mathrm{LR}=-\log 10\left(N_{f} / N_{0}\right)$

where $N_{f}$ corresponds to the bacterial concentration per unit area of support at $t=8 \mathrm{~h}$.

\section{Efficiency parameters}

To assess the influence of the irradiation conditions on the photocatalytic inactivation on $B$. subtilis spores and vegetative cells attached at the coated rings, the following efficiency parameters were calculated:

Photonic efficiency $\left(\boldsymbol{\eta}_{p h}\right)$ This parameter relates the photocatalytic inactivation rate with the rate of incident radiation. It can be expressed as (Zacarías et al. 2012):

$\eta_{\mathrm{ph}}=-\frac{\left.(d N / d t)\right|_{t=0} \times A_{c a t}}{\left\langle q_{i}\right\rangle_{A_{\mathrm{w}}} \times A_{\mathrm{W}}}$

where $(d N / d t)_{t=0}$ represents the initial rate of bacteria inactivation $\left[\mathrm{CFU} \mathrm{cm}{ }^{-2} \mathrm{~h}^{-1}\right], A_{\text {cat }}$ is the total $\mathrm{TiO}_{2}$-coated area of the glass rings inside the reactor $\left[\mathrm{cm}^{2}\right],\left\langle q_{i}\right\rangle$ is the incident radiation flux at the reactor window (internal or external) [Einstein $\mathrm{cm}^{-2} \mathrm{~h}^{-1}$ ], and $A_{\mathrm{w}}$ is the irradiated window area (the internal area of the reactor inner tube or the external area of the outer tube) $\left[\mathrm{cm}^{2}\right]$. When the reactor was irradiated with the inner and outer lamps simultaneously, the denominator of Eq. 6 was calculated as $\left[\left\langle q_{\mathrm{i}}\right\rangle_{A_{\mathrm{w}}} \times A_{\mathrm{w}}\right]$ int $+\left[\left\langle q_{\mathrm{i}}\right\rangle_{A_{\mathrm{w}}} \times A_{\mathrm{w}}\right]$ ext. $A_{\text {cat }}$ was calculated as the sum of the coated internal and external surface of the 600 glass rings in the packed bed.

Quantum efficiency $\left(\boldsymbol{\eta}_{q u}\right)$ It relates to the photocatalytic inactivation rate with the photon absorption rate. This parameter can be written as (Zacarías et al. 2019):

$\eta_{\mathrm{qu}}=-\frac{\left.(d N / d t)\right|_{t=0} \times A_{\mathrm{cat}}}{\left\langle e^{a, s}\right\rangle_{A_{\mathrm{cat}}} \times A_{\mathrm{cat}}}$

where $\left\langle e^{a, s}\right\rangle_{A_{\text {cat }}}$ is the local surface rate of photon absorption averaged over $A_{\text {cat }}$ [Einstein $\mathrm{cm}^{-2} \mathrm{~h}^{-1}$ ].

The initial rate of inactivation under each experimental condition was obtained by calculating the first derivative of the corresponding fitting equation (Eq. 3) at $t=0$.

$\left.(d N / d t)\right|_{t=0}=-N_{0} \times k$

The Monte Carlo method was employed to evaluate the photon absorption distribution inside the reactor and to compute the surface rate of photon absorption $\left(\left\langle e^{a, s}\right\rangle_{A_{\text {cat }}}\right)$. Briefly, this method consists of tracking the trajectory of a statistically significant number of photons inside the reactor until they are either absorbed or scattered out, and the spatial location of the absorbed photons is recorded. The direction, length of the trajectory, and fate of the photons are determined by random numbers. A photon travels with a linear trajectory through the reactor annular space until it finds a glass ring or the reactor 
walls. The distance that a photon can travel without reaching a ring is defined by the photon mean free path (Imoberdorf et al. 2010) and by a random number. If a photon reaches a $\mathrm{TiO}_{2}$ coated ring, three phenomena can take place: absorption, reflection, or transmission. If the photon is absorbed in the $\mathrm{TiO}_{2}$ film, the position is stored in a spatial cell, and the trajectory of a new photon is considered. If the photon is reflected, the new direction is determined by considering specular reflection (Imoberdorf et al. 2007). Finally, if the photon is transmitted, a new travelling distance is calculated. If the photon reaches the reactor windows without being absorbed, it can be reflected back inside the reactor space or transmitted outside the reactor. Considering the angular symmetry of the reactor, the annular reaction region was divided into $2 \mathrm{D}$ spatial cells to store the absorption places of the photons and to subsequently calculate the local surface rate of photon absorption. More details of the methodology employed can be found elsewhere (Zacarías et al. 2019; Manassero et al. 2017).

\section{Results and discussion}

\section{Monte Carlo simulations of the photon absorption rate inside the reactor}

The values of the radiation absorbed by the $\mathrm{TiO}_{2}$-coated glass inside the reactor, for the 3 irradiation conditions tested, are presented in Table 1. The values of radiation entering the reaction space through the windows, experimentally measured with a fibre optic spectrophotometer, are also shown in the table.

These results demonstrate that more than $60 \%$ of the incident radiant energy is absorbed inside the reactor under the 3 irradiation conditions. The fraction of radiation that is not absorbed by the photocatalytic rings is lost through the reactor ends $(20 \%)$ or through the reactor windows $(20 \%)$. These values were calculated from simulation results by taking into account the total number of photons analysed.

Figure 3 shows the absorbed radiation profiles inside the reactor filled with the $\mathrm{TiO}_{2}$ glass rings for the different irradiation conditions. As expected, the highest values of absorbed radiation are obtained next to the irradiated windows. When only inner or, alternatively, outer lamps are on, as we move

Table 1 Radiation simulation results

\begin{tabular}{lll}
\hline Irradiation condition & $\begin{array}{c}\left\langle q_{\mathrm{i}}\right\rangle_{\mathrm{A}_{\mathrm{w}}} \times A_{\mathrm{w}} \\
{\left[\text { Einstein } h^{-1}\right] \times 10^{3}}\end{array}$ & $\begin{array}{c}\left\langle e^{a, s}\right\rangle_{A_{\text {cat }}} \times A_{\text {cat }} \\
{\left[\text { Einstein } h^{-1}\right] \times 10^{3}}\end{array}$ \\
\hline Internal & 1.38 & 0.85 \\
External & 2.00 & 1.23 \\
Internal + external & 3.38 & 2.07 \\
\hline
\end{tabular}

inside the reactor bed, the absorbed radiation significantly decreases (Fig. $3 a$ and $b$ ). At the centre of the reaction space $(r=3.6 \mathrm{~cm})$, radiation absorption reaches approximately $10 \%$ of the value at the window, i.e., half reaction space is underilluminated. Conversely, when the reactor is irradiated from both sides, there is no location where radiation absorption is less than $25 \%$ of the value at the outer window (Fig. $3 \mathrm{c}$ ). This analysis shows that under-illumination from both sides, the distribution of radiation in the packed bed is more uniform, allowing a better utilization of the whole reactor volume.

\section{Filtration of microorganisms in the air stream}

The quantification of the CFU in the reactor outlet air showed that the value of viable spores remained approximately constant after 4 min of nebulization. $92 \pm 6 \%$ of the spores initially present in the air stream were retained inside the reactor. Taking into account that the concentration of bacteria employed in the inlet air stream $\left(2 \times 10^{4} \mathrm{CFU} \mathrm{m}^{-3}\right)$ is higher than the usual concentration of pathogens present in indoor air, we can affirm that almost all microorganisms can be filtered by passing one time through the packed-bed reactor.

\section{Photocatalytic inactivation of microorganisms in the air stream (with recirculation)}

The air stream containing the spores that were not filtered in the reactor bed was recirculated in the system under UV radiation (internal + external irradiation). Table 2 presents the results of spores' inactivation at different irradiation times.

As observed in the table, in less than $1 \mathrm{~h}$ of recirculation, spores were completely removed from the air stream. It is important to point out that the air was allowed to recirculate in the system with the lamps off after the end of the assays in order to evaluate the possible detachment of microorganisms. No viable spores were found in the air stream after $60 \mathrm{~min}$ of recirculation in the dark.

\section{Photocatalytic inactivation of microorganisms in the packed bed (without recirculation)}

Figure $4 \mathrm{a}$ shows the experimental concentration of viable spores attached to the coated glass rings vs irradiation time under different irradiation conditions. The corresponding fitting curves are also presented in the figure. Similarly, Fig. $4 \mathrm{~b}$ shows results of $B$. subtilis vegetative cells inactivation in the packed bed.

Both spores and vegetative cells inactivation are clearly enhanced by the irradiation level. Table 3 shows the inactivation percentage and the logarithmic reduction after $8 \mathrm{~h}$ of irradiation and the values of the apparent kinetic constant for both bacterial structures. As expected, the inactivation rate of vegetative cells is higher than that obtained for spores. After 


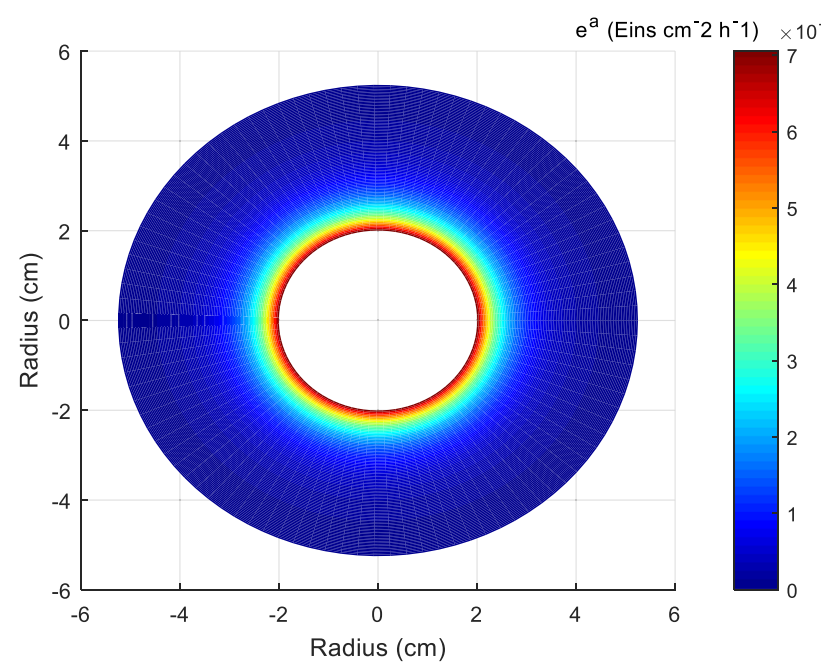

a

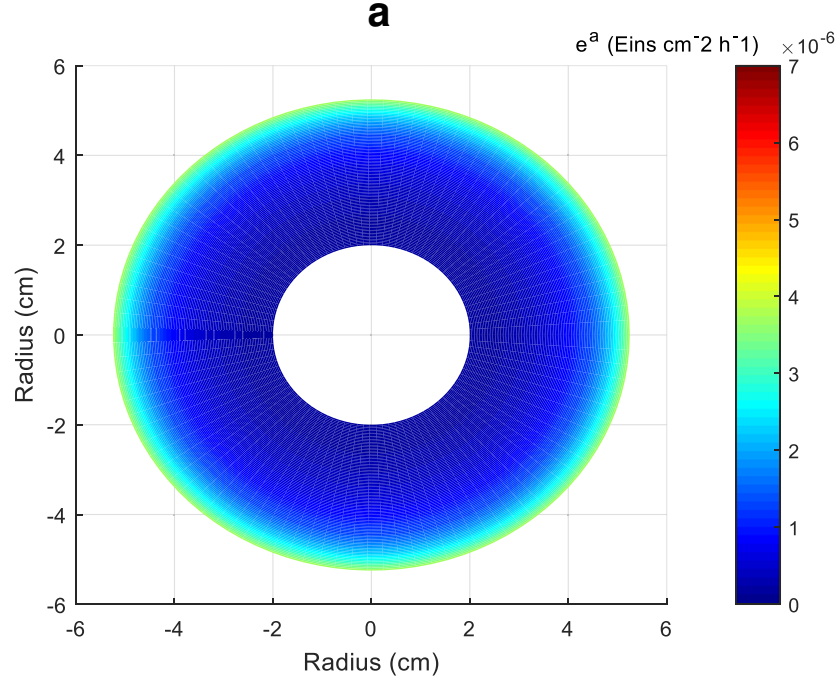

b

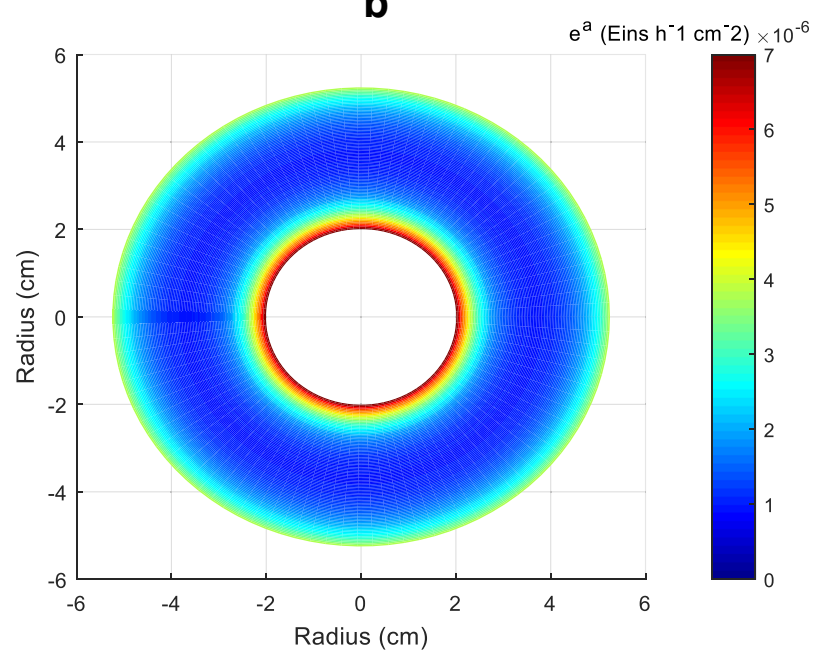

C

Fig. 3 Monte Carlo simulations of the absorbed radiation in the reactor under the different irradiation conditions. Radial profiles along the middle-length plane $(1.5 \mathrm{~cm}$ ). (a) Internal irradiation (only inner lamps on). (b) External irradiation (only outer lamps on). (c) Internal + external irradiation
Table 2 Inactivation percentage in the air stream

\begin{tabular}{ll} 
Irradiation time $(\mathrm{min})$ & $\%$ inactivated spores \\
\hline 20 & $60 \pm 7$ \\
40 & $74 \pm 8$ \\
60 & $100 \pm 2$ \\
80 & $100 \pm 2$ \\
\hline
\end{tabular}

$8 \mathrm{~h}$ of irradiation, 2 logs of reduction were obtained for vegetative cells, whereas spores only reached $0.5 \mathrm{LR}$.

To assess the utilization of radiant energy to inactivate the retained microorganisms inside the reactor, photonic and quantum efficiency parameters were calculated from Eqs. 6 and 7 , respectively. Both parameters, along with the initial inactivation rates under different irradiation conditions, are presented in Table 4.

Although the inactivation rate increases with the incident radiation rate and the photon absorption rate, this relationship is not proportional, as evidence by the values of $\eta_{\mathrm{ph}}$ and $\eta_{\mathrm{qu}}$. Similar efficiencies were obtained with internal and external irradiation separately. But under illumination from both sides, although inactivation rates increase, the denominators of Eqs. 6 and 7 increase more, and, therefore, efficiencies decrease around $20 \%$ for both bacterial structures. This behaviour is usually found in photocatalytic reactions, and it is attributed to the increase in the recombination rate of electrons and holes in the $\mathrm{TiO}_{2}$ particles at high irradiation levels. This effect originates a nonlinear relation (square root dependence) between the inactivation rate and the radiation absorption rate. Consequently, efficiencies drop (Hoffman et al. 1994; Satuf et al. 2007; Motegh et al. 2010).

\section{Conclusions}

The performance of a packed-bed photocatalytic reactor for air disinfection has been analysed. The reactor can completely remove vegetative cells and resistant forms of $B$. subtilis from the air by combining filtration and photocatalytic inactivation. One hundred percent elimination of bacterial spores in the air stream can be reached by $1 \mathrm{~h}$ of recirculation inside the irradiated reactor. Nevertheless, when all microorganisms have been removed from the air stream, a high percentage of the filtered bacteria is still viable inside the reactor. Long irradiation times are needed to completely inactivate the spores attached at the photocatalytic rings. Better utilization of the reaction space is achieved when the reactor is irradiated from both sides, reaching higher inactivation rates, although efficiency parameters slightly decrease. After $8 \mathrm{~h}$ of irradiation under this condition, the initial concentration of retained spores and vegetative cells was reduced by $68 \%$ and $99 \%$, 


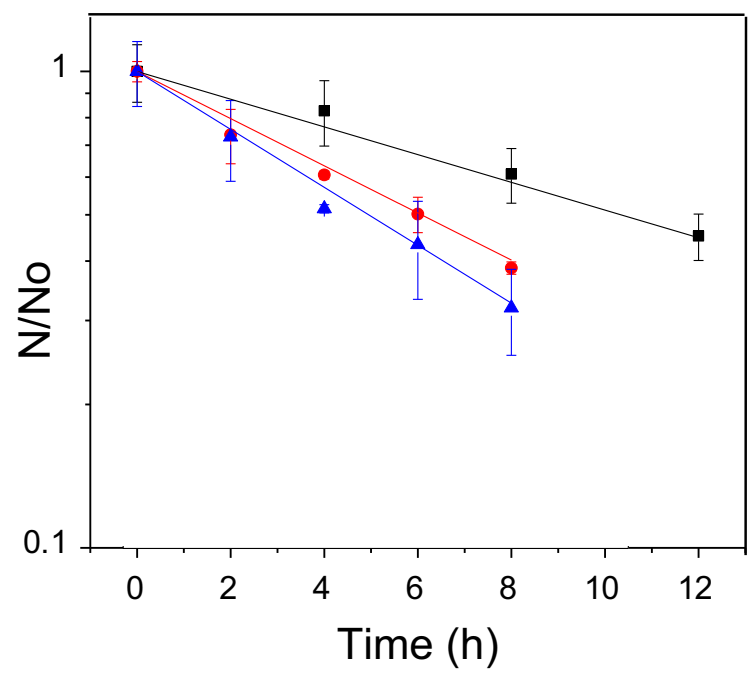

a

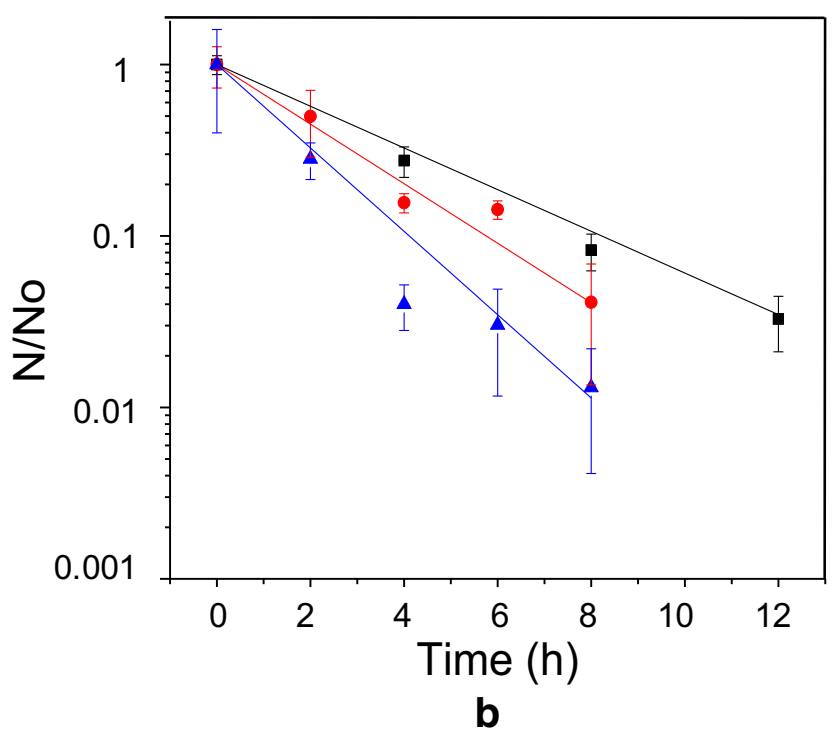

Fig. 4 Bioaerosol inactivation in the packed bed under different irradiation conditions. Fittings are depicted with solid lines, and experimental values are depicted with the following symbols: squares (internal irrad), circles (external irrad), triangles (internal + external irrad). Error bars represent $99 \%$ confidence interval. (a) Spore inactivation. (b) Vegetative cell inactivation

Table 3 Photocatalytic inactivation in the packed bed

\begin{tabular}{llll}
\hline Irradiation condition & Inactivation $\%$ & $L R$ & $k\left(h^{-1}\right)$ \\
\hline Spores & & & \\
Internal & 39 & 0.2 & $0.07 \pm 0.01$ \\
External & 61 & 0.4 & $0.11 \pm 0.01$ \\
Internal + external & 68 & 0.5 & $0.14 \pm 0.01$ \\
Vegetative cells & & & \\
Internal & 92 & 1.1 & $0.28 \pm 0.01$ \\
External & 96 & 1.4 & $0.40 \pm 0.03$ \\
Internal + external & 99 & 2.0 & $0.56 \pm 0.04$ \\
\hline
\end{tabular}

Table 4 Efficiency parameters

Parameters

\begin{tabular}{|c|c|c|c|}
\hline $\begin{array}{l}\text { Irradiation } \\
\text { condition }\end{array}$ & $\begin{array}{l}-\left.(d N / d t)\right|_{t=0} \times A_{\text {cat }} \\
{\left[\mathrm{CFU} \mathrm{h}^{-1}\right] \times 10^{-7}}\end{array}$ & $\begin{array}{l}\eta_{\mathrm{ph}} \\
{\left[\begin{array}{cc}\mathrm{C} & \mathrm{F} \\
\left.\text { Einstein }^{-1}\right] \times \\
10^{-9}\end{array}\right.}\end{array}$ & 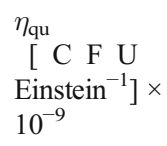 \\
\hline \multicolumn{4}{|l|}{ Spores } \\
\hline Internal & $0.8 \pm 0.1$ & $5.8 \pm 0.7$ & $9.4 \pm 1.0$ \\
\hline External & $1.3 \pm 0.1$ & $6.5 \pm 0.5$ & $10.6 \pm 0.8$ \\
\hline $\begin{array}{r}\text { Internal + } \\
\text { external } \\
\text { Vegetative }\end{array}$ & $1.7 \pm 0.1$ & $5.0 \pm 0.3$ & $8.2 \pm 0.5$ \\
\hline Internal & $3.4 \pm 0.1$ & $25 \pm 1$ & $41 \pm 1$ \\
\hline External & $4.8 \pm 0.4$ & $24 \pm 2$ & $39 \pm 3$ \\
\hline $\begin{array}{r}\text { Internal + } \\
\text { external }\end{array}$ & $6.7 \pm 0.5$ & $20 \pm 1$ & $32 \pm 2$ \\
\hline
\end{tabular}

respectively. $\mathrm{TiO}_{2}$-coated glass rings have proven to be an excellent packing material for photocatalytic reactors employed in bioaerosol disinfection. They have high filtration capacity, they provide low pressure drop, they can be reused without appreciable loss of activity, and microorganisms do not detached easily from them.

Acknowledgements The authors are grateful to the Universidad Nacional del Litoral (UNL, CAI+D 50020150100020LI, CAI+D 50420150100009LI), Consejo Nacional de Investigaciones Científicas y Técnicas (CONICET, PIP N 1122015 0100093), and Agencia Nacional de Promoción Científica y Tecnológica (ANPCyT, PICT-2014-1020) for financial support. We also thank Antonio C. Negro for his valuable help during the experimental work.

Authors' contributions SMZ, OMA, and MLS contributed to the study conception and design. Experimental assays and data collection were performed by SMZ and SP. Data analysis and interpretation was performed by SMZ, AM, OMA, and MLS. The first draft of the manuscript was written by SMZ, AM, and MLS. All authors read and approved the final manuscript.

Funding Universidad Nacional del Litoral (UNL): CAI+D 50020150100020LI, CAI+D 50420150100009LI.

Consejo Nacional de Investigaciones Científicas y Técnicas (CONICET): PIP Nº 11220150100093.

Agencia Nacional de Promoción Científica y Tecnológica (ANPCyT): PICT-2014-1020.

Data availability The datasets used and/or analysed during the current study are available from the corresponding author on reasonable request.

\section{Compliance with ethical standards}

Competing interests The authors declare that they have no competing interests.

Ethics approval and consent to participate Not applicable. 
Consent for publication Not applicable.

\section{References}

Akach J, Ochieng A (2018) Monte Carlo simulation of the light distribution in an annular slurry bubble column photocatalytic reactor. Chem Eng Res Des 129:248-258. https://doi.org/10.1016/j.cherd. 2017.11.021

Assadi AA, Bouzaza A, Wolbert D, Petit P (2014) Isovaleraldehyde elimination by $\mathrm{UV} / \mathrm{TiO}_{2}$ photocatalysis: comparative study of the process at different reactors configurations and scales. Environ Sci Pollut Res 21:11178-11188. https://doi.org/10.1007/s11356-0142603-7

Atrih A, Foster SJ (2002) Bacterial endospores the ultimate survivors. Int Dairy J 12:217-223. https://doi.org/10.1016/S0958-6946(01) 00157-1

Blake DM, Maness P-C, Huang Z, Wolfrum EJ, Huang J (1999) Application of the photocatalytic chemistry of titanium dioxide to disinfection and the killing of cancer cells. CAS Cource Index (CASSI): Sep Purif Methods 28:1-50. https://doi.org/10.1080/ 03602549909351643

Costa Filho BM, Vilar VJP (2019) Strategies for the intensification of photocatalytic oxidation processes towards air streams decontamination: a review. Chem Eng J 391:123531. https://doi.org/10.1016/j. cej.2019.123531

Doss N, Carré G, Keller V, André P, Keller N (2018) Photocatalytic decontamination of airborne T2 bacteriophage viruses in a smallsize $\mathrm{TiO}_{2} / \beta$-SiC alveolar foam LED reactor. Water Air Soil Pollut 229:29. https://doi.org/10.1007/s11270-017-3676-y

Hoffman AJ, Carraway ER, Hoffmann MR (1994) Photocatalytic production of $\mathrm{H}_{2} \mathrm{O}_{2}$ and organic peroxides on quantum-sized semiconductor colloids. Environ Sci Technol 28:776-785. https://doi.org/ 10.1021/es00054a006

Horie Y, Taya M, Tone S (1998a) Effect of cell adsorption on photosterilization of Escherichia coli over titanium dioxideactivated charcoal granules. J Chem Eng Jpn 31:922-929. https:// doi.org/10.1252/jcej.31.922

Horie Y, Taya M, Tone S (1998b) Evaluation of photocatalytic sterilization rates of Escherichia coli cells in titanium dioxide slurry irradiated with various light sources. J Chem Eng Jpn 31:577-584. https:// doi.org/10.1252/jcej.31.577

Imoberdorf GE, Alfano OM, Cassano AE, Irazoqui HA (2007) Monte Carlo model of UV-radiation interaction with $\mathrm{TiO}_{2}$-coated spheres. AIChE J 53:2688-2703. https://doi.org/10.1002/aic.11289

Imoberdorf GE, Vella G, Sclafani A, Rizzuti L, Alfano OM, Cassano AE (2010) Radiation model of a $\mathrm{TiO}_{2}$-coated, quartz wool, packed-bed photocatalytic reactor. AIChE J 56:1030-1044. https://doi.org/10. 1002/aic. 11863

Josset S, Taranto J, Keller N, Keller V, Lett M-C (2010) Photocatalytic treatment of bioaerosols: impact of the reactor design. Environ Sci Technol 44:2605-2611. https://doi.org/10.1021/es902997v

Kim J, Jang J (2018) Inactivation of airborne viruses using vacuum ultraviolet photocatalysis for a flow-through indoor air purifier with short irradiation time. Aerosol Sci Technol 52:557-566. https://doi. org $/ 10.1080 / 02786826.2018 .1431386$

Li P, Li J, Feng X, Li J, Hao Y, Zhang J, Wang H, Yin A, Zhou J, Ma X, Wang B (2019) Metal-organic frameworks with photocatalytic bactericidal activity for integrated air cleaning. Nat Commun 10:1-10. https://doi.org/10.1038/s41467-019-10218-9

Luengas A, Barona A, Hort C, Gallastegui G, Platel V, Elias A (2015) A review of indoor air treatment technologies. Rev Environ Sci Biotechnol 14:499-522. https://doi.org/10.1007/s11157-015-93639
Manassero A, Satuf ML, Alfano OM (2017) Photocatalytic degradation of an emerging pollutant by $\mathrm{TiO} 2$-coated glass rings: a kinetic study. Environ Sci Pollut Res 24:6031-6039. https://doi.org/10.1007/ s11356-016-6855-2

Marugán J, van Grieken R, Pablos C, Satuf ML, Cassano AE, Alfano OM (2015) Photocatalytic inactivation of Escherichia coli aqueous suspensions in a fixed-bed reactor. Catal Today 252:143-149. https:// doi.org/10.1016/j.cattod.2014.10.031

Moreira J, Serrano B, Ortíz A, de Lasa H (2010) Evaluation of photon absorption in an aqueous $\mathrm{TiO}_{2}$ slurry reactor using Monte Carlo simulations and macroscopic balance. Ind Eng Chem Res 49: 10524-10534. https://doi.org/10.1021/ie100374f

Motegh M, Cen J, Appel PW, van Ommen JR, Kreutzer MT (2010) Photocatalytic reactor efficiencies and simplified expressions to assess their relevance in kinetic experiments. Chem Eng J 207-208: 607-615. https://doi.org/10.1016/j.cej.2012.07.023

Pal A, Min X, Yu LE, Pehkonen SO, Ray M (2005) Photocatalytic inactivation of bioaerosols by $\mathrm{TiO}_{2}$ coated membrane. Int $\mathrm{J}$ Chem React Eng 3:A45. https://doi.org/10.2202/1542-6580.1236

Ren H, Koshy P, Chen W-F, Qi S, Sorrell CC (2017) Photocatalytic materials and technologies for air purification. J Hazard Mater 325:340-366. https://doi.org/10.1016/j.jhazmat.2016.08.072

Rodrigues-Silva C, Miranda SM, Lopes FVS, Silva M, Dezotti M, Silva AMT, Faria JL, Boaventura RAR, Vilar VJP, Pinto E (2016) Bacteria and fungi inactivation by photocatalysis under UVA irradiation: liquid and gas phase. Environ Sci Pollut Res 24:6372-6381. https://doi.org/10.1007/s11356-016-7137-8

Satuf ML, Brandi RJ, Cassano AE, Alfano OM (2007) Quantum efficiencies of 4-chlorophenol photocatalytic degradation and mineralization in a well-mixed slurry reactor. Ind Eng Chem Res 46:43-51. https://doi.org/10.1021/ie0604019

Shehata TE, Collins EB (1972) Sporulation and heat resistance of psychrophilic strains of Bacillus. J Dairy Sci 55:1405-1409. https://doi. org/10.3168/jds.S0022-0302(72)85684-4

USEPA (U.S. Environmental Protection Agency) (1989) Report to congress on indoor air quality, vol 2. EPA/400/1-89/001C. Washington, DC. https://www.epa.gov/report-environment/indoor-air-quality

Vohra A, Goswami DY, Deshpande DA, Block SS (2005) Enhanced photocatalytic inactivation of bacterial spores on surfaces in air. $\mathrm{J}$ Ind Microbiol Biotechnol 32:364-370. https://doi.org/10.1007/ s10295-005-0006-y

Yu K-P, Lee GW-M, Lin S-Y, Huang CP (2008) Removal of bioaerosols by the combination of a photocatalytic filter and negative air ions. $\mathrm{J}$ Aerosol Sci 39:377-392. https://doi.org/10.1016/j.jaerosci.2007.12. 005

Zacarías SM, Vaccari MC, Alfano OM, Irazoqui HA, Imoberdorf GE (2010) Effect of the radiation flux on the photocatalytic inactivation of spores of Bacillus subtilis. J Photochem Photobiol A Chem 214: 171-180. https://doi.org/10.1016/j.jphotochem.2010.06.021

Zacarías SM, Satuf ML, Vaccari MC, Alfano OM (2012) Efficiency evaluation of different $\mathrm{TiO}_{2}$ coatings on the photocatalytic inactivation of airborne bacterial spores. Ind Eng Chem Res 51:13599 13608. https://doi.org/10.1021/ie3009956

Zacarías SM, Pirola S, Manassero A, Visuara ME, Alfano OM, Satuf ML (2019) Photocatalytic inactivation of bioaerosols in a fixed-bed reactor with $\mathrm{TiO}_{2}$-coated glass rings. Photochem Photobiol Sci 18: 884-890. https://doi.org/10.1039/c8pp00297e

Zazueta ALL, Destaillats H, Li Puma G (2013) Radiation field modeling and optimization of a compact and modular multi-plate photocatalytic reactor (MPPR) for air/water purification by Monte Carlo method. Chem Eng J 217:475-485. https://doi.org/10.1016/j.cej. 2012.11.085

Publisher's note Springer Nature remains neutral with regard to jurisdictional claims in published maps and institutional affiliations. 